\title{
Susceptibility to diabetic neuropathy in patients with insulin dependent diabetes mellitus is associated with a polymorphism at the $5^{\prime}$ end of the aldose reductase gene
}

\author{
Angela E Heesom, Ann Millward, Andrew G Demaine
}

\begin{abstract}
Objectives-There is evidence that the polyol pathway is involved in the pathogenesis of diabetic neuropathy. Aldose reductase (ALR2) is the first and rate limiting enzyme of this pathway and recent studies have suggested that polymorphisms in and around the gene are associated with the development of diabetic microvascular disease. The aim was to examine the role of ALR2 in the susceptibility to diabetic neuropathy in patients with insulin dependent diabetes mellitus (IDDM).
\end{abstract}

Methods-One hundred and fifty nine British white patients with IDDM and 102 normal healthy controls were studied using the polymerase chain reaction to test for a highly polymorphic microsatellite marker 2.1 kilobase (kb) upstream of the initiation site of the ALR2 gene.

Results-Seven alleles were detected (Z-6, $Z-4, Z-2, Z, Z+2, Z+4$, and $Z+6)$. There was a highly significant decrease in the frequency of the $Z+2$ allele in those patients with overt neuropathy compared with those with no neuropathy after 20 years duration of diabetes $\left(14.1 \% \quad v 38.2 \%, \chi^{2}\right.$ $=17.3$, p <0.00001). A similar difference was also found between the neuropathy group and those patients who have had diabetes for $<$ five years with no overt neuropathy $\left(14.1 \% v 30.2 \%, \chi^{2}=9.0, \mathrm{p}<0.0025\right)$. The neuropathy group also had a significant decrease in the frequency of the $\mathrm{Z} / \mathrm{Z}+2$ genotype compared with those patients who have no neuropathy after 20 years duration of diabetes $(14.0 \% v 44.7 \%$, $\left.\chi^{2}=13.0, p<0.0005\right)$.

Conclusion-These results suggest that the aldose reductase gene is intimately involved in the pathogenesis of diabetic neuropathy.

(F Neurol Neurosurg Psychiatry 1998;64:213-216)

Keywords: insulin dependent diabetes mellitus; diabetic neuropathy; aldose reductase; chromosome 7q35

Diabetic neuropathy is an extremely common complication in patients with insulin dependent diabetes mellitus (IDDM) with a prevalence of about $25 \%-30 \% .{ }^{1}$ Although the cause of diabetic neuropathy is still unknown, it is well recognised that the degree and duration of hyperglycaemia correlates with the appearance and severity of the damage to the nervous tissue. ${ }^{2}$ Whereas poor glycaemic control is a major determinant of susceptibility and severity to neuropathy, it is now recognised that both metabolic and vascular factors play an essential part. ${ }^{4-7}$ There is ample evidence to implicate the involvement of the sorbitol or polyol pathway in the pathogenesis of diabetic neuropathy. ${ }^{8-10}$ The polyol pathway converts glucose to fructose utilising the enzymes aldose reductase (ALR2) and sorbitol dehydrogenase. The diabetic milieu results in an accumulation of sorbitol in the cell leading to a cascade of metabolic abnormalities causing hypoxia, pseudohypoxia, and tissue ischaemia. ${ }^{11-14}$ It has recently been shown that mice transgenic for human aldose reductase develop a galactosaemic neuropathy along with structural and functional changes similar to those found in diabetic animals. ${ }^{15}$

The cDNA and genomic sequence of the aldose reductase gene (ALR2) has been isolated from various tissues in several species including humans. The functional gene is situated on chromosome $7 \mathrm{q} 35$ and consists of 10 exons which span 18 kilobases $(\mathrm{kb})$ of DNA. ${ }^{16-20}$ Non-functional copies of the ALR2 gene have also been identified. ${ }^{21}$

It has previously been reported that polymorphisms of the ALR2 and the adjacent TCRBC locus are associated with susceptibility to diabetic microvascular complications in patients with IDDM. ${ }^{22-24}$ Recently, a dinucleotide repeat polymorphic marker (microsatellite) was located $2.1 \mathrm{~kb}$ upstream of the transcription start site of the ALR2 gene and was found to be associated with diabetic nephropathy in a white IDDM population and with retinopathy in patients of Chinese origin with non-insulin dependent diabetes mellitus (NIDDM). ${ }^{25}{ }^{26}$ We have employed this microsatellite marker to study a large population of patients with IDDM and overt diabetic neuropathy.

\section{Materials and methods}

PATIENTS AND CONTROL SUBJECTS

Samples of DNA from 159 British white patients with IDDM as defined by the National Diabetes Data Group ${ }^{27}$ who had attended the diabetic clinic (Dr Millward) were randomly taken from the freezer for analysis. One hundred and two normal healthy British white subjects provided control samples. These comprised 40 cord blood samples collected in revised form 22 August 1997

Accepted 29 August 1997 
Table 1 Clinical features of the patient groups and normal controls

\begin{tabular}{|c|c|c|c|c|}
\hline & \multicolumn{3}{|l|}{ Patient subgroup } & \multirow{2}{*}{$\begin{array}{l}\text { Normal } \\
\text { controls }\end{array}$} \\
\hline & Uncomplicated & Short duration & Neuropathic patients & \\
\hline Male:female & $17: 21$ & $17: 26$ & $42: 36$ & $43: 59$ \\
\hline $\begin{array}{l}\text { Age at onset of } \\
\text { diabetes (y) }\end{array}$ & $17.7(9.3)(0-36)$ & $\begin{array}{l}17.2(10.8) \\
(0-42)\end{array}$ & $20.7(11.7)(1-58)$ & \\
\hline Duration of disease $(\mathrm{y})$ & $31.1(9.4)(20-56)$ & $2.4(1.1)(1-5)$ & $28.5(8.5)(12-50)$ & \\
\hline
\end{tabular}

The results are expressed as mean (SD) (range).

Uncomplicated $=$ patients who have had insulin dependent diabetes mellitus (IDDM) for $>20$ y yet remain free of retinopathy and proteinuria; short duration $=$ patients who have had IDDM for

$<5$ years and remain free of retinopathy and proteinuria; neuropathic patients $=$ clinical evidence of peripheral or autonomic neuropathy. Peripheral neuropathy was defined clinically (symptoms of pain, numbness or paraesthesiae in feet or hands, loss of vibration sense, light touch or pin prick, and temperature, loss of ankle reflexes, evidence of past or present foot ulceration). Autonomic neuropathy was diagnosed if there was orthostatic hypotension, gastroparesis, or a flaccid neuropathic bladder.

The normal controls consist of samples from random healthy white blood donors, school children aged between 5 and 16, and sequential cord blood samples.

sequentially after normal obstetric delivery from the labour ward, Derriford Hospital, Plymouth; 44 samples from schoolchildren aged between 5 and 16 years; and 18 samples from healthy adult donors. Local ethics committee approval had been obtained.

The patients were classified according to their microvascular complications as previously described. ${ }^{22-24}$

\section{Uncomplicated patients $(n=38)$}

These patients had had IDDM for at least 20 years but remained free of retinopathy (fewer than five dots or blots per fundus) and proteinuria (urine Albustix negative on three consecutive occasions over 12 months).

Short duration patients ( $n=43$ )

These patients had had IDDM for fewer than five years and remained free of retinopathy, proteinuria, and overt neuropathy.

Diabetic neuropathy patients $(n=78)$

Overt neuropathy was defined if there was any clinical evidence of peripheral or autonomic neuropathy. Peripheral neuropathy was defined clinically; most of the patients having all of the following: (a) symptoms of pain, numbness, or paraesthesiae in the feet, or hands, or both; $(b)$ sensory signs such as loss of vibration sense as assessed with a tuning fork, light touch, or pin prick, and temperature using warm and cold stimuli; (c) loss of ankle reflexes; (d) evidence of past or present neuropathic foot ulceration.

Autonomic neuropathy was diagnosed if there was orthostatic hypotension, gastroparesis, or a flaccid neuropathic bladder. None of these patients had another obvious cause of peripheral neuropathy as they had negative syphilis serology and autoimmune profiles for vasculitis, and vitamin B12 and folate concentrations were within normal limits.

Thirty seven of a total of 78 patients $(47 \%)$ had both peripheral and autonomic neuropathy. Thirty seven patients of $78(47 \%)$ had peripheral neuropathy only; the remaining four (5\%) patients had autonomic neuropathy alone.

Table 1 shows the clinical features of these patients.
PREPARATION OF DNA AND ANALYSIS OF THE MICROSATELLITE POLYMORPHISM

High molecular weight DNA was prepared from $15-20 \mathrm{ml}$ of peripheral blood using Nucleon extraction kits (Scotlab, Paisley, Scotland). An aliquot (50-250 ng) of this DNA was then amplified using the polymerase chain reaction (PCR). Briefly, a pair of oligonucleotide primers were constructed which flank a 138 base pair (bp) region (5'ALR2) which contains the dinucleotide $(\mathrm{CA})_{\mathrm{n}}$ repeat. $^{26}$ The antisense primer was labelled with ${ }^{32} \mathrm{P}$-dATP (Amersham UK) by T4 polynucleotide kinase (Pharmacia Biotech). The amplification reaction was performed

in $50 \mu \mathrm{l}$ volumes containing the end labelled ARpr1 primer (5'-GAATCTTAACATGCTCTGAACC), ARpr2 primer (5'-GCCCCAGCCCTATACCTAG), $10 \mathrm{mM}$ dNTPs (Pharmacia), 10X buffer solution, and 1 unit Taq polymerase (HT Biotech UK). The samples were subjected to 30 cycles of amplification in a two step reaction which consisted of denaturation for one minute at $94^{\circ} \mathrm{C}$ and annealing extension for one minute at $61^{\circ} \mathrm{C}$ in a Techne thermal cycler.

An aliquot of the amplified DNA was electrophoresed through a $5 \%$ formamide/urea polyacrylamide gel (National Diagnostics US) at $90 \mathrm{~W}$ for three hours and subsequently dried and autoradiography performed using Kodak $\mathrm{X}$-Omat film with intensifying screens at $-85^{\circ} \mathrm{C}$ for $10-16$ hours.

STATISTICAL ANALYSIS

The frequency of 5'ALR2 alleles and genotypes in the patient subgroups and normal controls were compared using the $\chi^{2}$ test and $2 \times 2$ contingency tables. The $\mathrm{p}$ values were corrected for the number of comparisons made (pc) using the Bonferroni inequality method ${ }^{28}$ and pc values of $<0.05$ were considered to be significant. When appropriate, the odds ratios were calculated.

\section{Results}

Seven alleles $(Z-6, Z-4, Z-2, Z, Z+2, Z+4$, and $Z+6)$ at the 5'ALR2 locus were detected in the patient and control populations. Table 2 shows the frequency of the 5'ALR2 alleles in the patient subgroups and normal controls. There was a highly significant increase in the frequency of the $Z+2$ allele in those patients without overt neuropathy, retinopathy, or proteinuria after 20 years duration of diabetes (uncomplicated) compared with those patients with neuropathy $(38.2 \% v 14.1 \%$ respectively, $\left.\chi^{2}=17.3, \mathrm{p}<0.00001, \mathrm{pc}=0.0001\right)$. A similar difference was also found between the short duration (patients who have had diabetes for $<5$ years without overt neuropathy, retinopathy or nephropathy) and the neuropathy group $\left(30.2 \% v 14.1 \%\right.$ respectively, $\chi^{2}=9.0$, $\mathrm{p}<0.0025, \mathrm{pc}=0.025)$. The increased frequency of the $\mathrm{Z}+2$ allele in the uncomplicated group was accompanied by a decrease in the Z-2 allele. By contrast, the Z-2 allele was significantly increased in the neuropathy group compared with the former group $(30.2 \% v$ $11.8 \%$ respectively, $\chi^{2}=9.3, \quad \mathrm{p}<0.0025$, 
Table 2 Frequency (\%) of 5'ALR2 microsatallite alleles in patients with insulin dependent diabetes mellitus and normal controls

\begin{tabular}{lllll}
\hline & Patient subgroup & & \\
\cline { 2 - 4 } Allele & $\begin{array}{l}\text { Uncomplicated } \\
(n=76)\end{array}$ & $\begin{array}{l}\text { Short duration } \\
(n=86)\end{array}$ & $\begin{array}{l}\text { Neuropathic patients } \\
(n=156)\end{array}$ & $\begin{array}{l}\text { Controls } \\
(n=204)\end{array}$ \\
\hline$Z-6$ & $0.0(0)$ & $0.0(0)$ & $1.3(2)$ & $1.9(4)$ \\
$Z-4$ & $1.3(1)$ & $8.1(7)$ & $7.7(12)$ & $4.4(9)$ \\
$Z-2$ & $11.8(9)$ & $19.8(17)$ & $30.2 \ddagger(47)$ & $22.1(45)$ \\
$Z$ & $38.2(29)$ & $39.5(34)$ & $42.9(67)$ & $44.1(90)$ \\
$Z+2$ & $38.2(29)$ & $30.2(26)$ & $14.1^{\star} \dagger(22)$ & $23.5(48)$ \\
$Z+4$ & $7.9(6)$ & $2.3(2)$ & $3.8(6)$ & $2.3(2)$ \\
$Z+6$ & $2.6(2)$ & $0.0(0)$ & $0.0(0)$ & $1.9(4)$ \\
\hline
\end{tabular}

$\mathrm{n}=$ Number of chromosomes. The number in parentheses is the number of chromosomes.

$\star v$ Frequency in uncomplicated $\chi^{2}=17.3, \mathrm{p}<0.00001, \mathrm{pc}=0.0001$.

$\dagger v$ Frequency in short duration $\chi^{2}=9.0, \mathrm{p}<0.0025, \mathrm{pc}=0.025$.

$\ddagger v$ Frequency in uncomplicated $\chi^{2}=9.3, \mathrm{p}<0.0025, \mathrm{pc}=0.025$.

Table 3 Frequency (\%) of 5'ALR2 microsatallite genotypes in patients with insulin dependent diabetes mellitus and normal controls

\begin{tabular}{lllll}
\hline & \multicolumn{2}{l}{ Patient subgroup } & & \\
\cline { 2 - 3 } Genotype & $\begin{array}{l}\text { Uncomplicated } \\
(n=38)\end{array}$ & $\begin{array}{l}\text { Short duration } \\
(n=43)\end{array}$ & $\begin{array}{l}\text { Neuropathic patients } \\
(n=78)\end{array}$ & $\begin{array}{l}\text { Controls } \\
(n=102)\end{array}$ \\
\hline $\mathrm{Z} / \mathrm{Z}$ & $10.5(4)$ & $16.3(7)$ & $14.1(11)$ & $25.5(26)$ \\
$\mathrm{Z}-2 / \mathrm{Z}-2$ & $2.6(1)$ & $9.3(4)$ & $10.3(8)$ & $9.8(10)$ \\
$\mathrm{Z}+2 / \mathrm{Z}+2$ & $10.5(4)$ & $14.0(6)$ & $1.3(1)$ & $11.8(12)$ \\
$\mathrm{Z} / \mathrm{Z}-2$ & $10.5(4)$ & $14.0(6)$ & $30.8+(24)$ & $15.7(16)$ \\
$\mathrm{Z} / \mathrm{Z}+2$ & $44.7(17)$ & $20.9(9)$ & $14.0^{\star}(11)$ & $17.6(18)$ \\
$\mathrm{Z}-2 / \mathrm{Z}+2$ & $5.3(2)$ & $4.6(2)$ & $7.7(11)$ & $4.9(5)$ \\
Other & $15.8(6)$ & $20.9(9)$ & $21.8(17)$ & $14.7(15)$
\end{tabular}

Numbers in parentheses are the actual numbers.

* Frequency in uncomplicated $v$ neuropathic patients $\chi^{2}=13, \mathrm{p}<0.0005, \mathrm{pc}=0.005$

† Frequency in short duration $v$ neuropathic patients $\chi^{2}=7.2, \mathrm{p}<0.01, \mathrm{pc}=\mathrm{NS}$.

$\mathrm{pc}=0.025)$. There were no significant differences between the neuropathy group and the normal controls.

Table 3 shows the frequency of the 5'ALR2 genotypes in the patients and normal controls. The uncomplicated group of patients had a significantly increased frequency of the $\mathrm{Z} / \mathrm{Z}+2$ 5'ALR2 genotype compared with the neuropathy group $(44.7 \%$ v $14.0 \%$ respectively, $\mathrm{p}<0.0005, \mathrm{pc}=0.005)$. There was a concomittant increase in the frequency of the $\mathrm{Z} / \mathrm{Z}-2$ 5'ALR2 genotype in the neuropathy group compared with the uncomplicated group although this difference was not significant after correction of the $\mathrm{p}$ value $(30.8 \% \quad v 10.5 \%$ respectively, $\left.\chi^{2}=7.2 \mathrm{p}<0.01, \mathrm{pc}=\mathrm{NS}\right)$. The frequency of the 5'ALR2 genotypes in the short duration and the neuropathy gropups were not significantly different from the normal controls. The frequency of the $\mathrm{Z} / \mathrm{Z}+2$ genotype in the uncomplicated group was significantly higher than in the normal controls $(44.7 \% v$ $17.6 \%$ respectively, $\chi^{2}=10.8, \quad \mathrm{p}<0.001$, $\mathrm{pc}=0.01)$. There were no significant differences in the frequency of the 5'ALR2 alleles and genotypes between those patients with peripheral and autonomic neuropathy alone (data not shown). This suggests that the 5'ALR2 locus is associated with peripheral neuropathy rather than autonomic neuropathy.

\section{Discussion}

It has previously been suggested that aldose reductase and the polyol pathway play critical parts in the development of diabetic neuropathy. A depletion of myoinositol has long been thought to be the underlying defect responsible for decreased nerve conduction velocity in experimental diabetes. ${ }^{29-31}$ The peripheral nerve in diabetic rats displays an accumulation of sorbitol and fructose along with a depletion in the level of myoinositol. ${ }^{32-34}$ Endoneurial microvessels and nerve fibres are particularly rich in aldose reductase, abnormalities in sorbitol and myoinositol metabolism, and sodium-potassium ATPase activity may contribute to the pathogenesis of diabetic neuropathy. ${ }^{35}$ Changes in nerve conduction can be reversed by the inclusion of an aldose reductase inhibitor, ${ }^{36}$ although the efficacy of aldose reductase inhibitors in the treatment of diabetic neuropathy in humans is uncertain. ${ }^{37}$ It has still to be proved whether the findings in animal models of diabetic neuropathy mirror those changes seen in humans. Whereas there is evidence that nerve sorbitol content is inversely proportional to the number of myelinated fibres seen in diabetic patients with neuropathy, ${ }^{38}$ there is no substantial evidence to show that a reduction in the level of myoinositol occurs in neuropathy in humans. ${ }^{3638}$ Alternatively, increased flux through the polyol pathway may be causing osmotic stress and swelling in one or more types of peripheral nerve cells leading to progressive nerve fibre damage. ${ }^{539}$ Non-ionic compounds such as sorbitol and myoinositol may have important physiological roles in the osmoregulation of the renal medulla. ${ }^{40}$ Alterations in the expression of the ALR2 gene or modifications of the membrane transporters such as the Na-myoinositol transporter may lead to changes in the intracellular concentrations of osmolytes causing osmotic stress in the nerve. ${ }^{41}$

An increased flux through the polyol pathway may result in metabolic defects caused by increased NADPH/NADP and NAD/NADH ratios, causing oxidative stress. The reduced availability of these cofactors for enzymes involved in free radical scavenging - such as glutathione reductase - together with those for vasodilatation - for example, endothelial nitric oxide synthase-would ultimately lead to tissue hypoxia and ischaemia. There is a growing body of evidence that nerve ischaemia plays an important part in the pathogenesis of diabetic neuropathy. ${ }^{71113}$ For instance, vasoconstriction can be overcome by giving vasodilatory agents such as $\alpha$-adrenergic receptor inhibitors and angiotensin converting enzyme inhibitors.

The results presented here strongly support a role for the polyol pathway in the pathogenesis of diabetic neuropathy. It has previously been shown that increased enzymatic activity is associated with diabetic microvascular disease in patients with IDDM and NIDDM diabetes. ${ }^{42}{ }^{43}$ Our results suggest that these differences in the enzyme activity may be due to genetic factors rather than the diabetes milieu. The osmoregulatory elements (OREs) of the ALR2 gene have been isolated and characterised and shown to be responsive to increasing concentrations of $\mathrm{NaCl}$. A functional ORE (AR-ORE) has recently been cloned and is situated within $1 \mathrm{~kb}$ of the 5'ALR2 locus. ${ }^{44}$ Therefore, the $\mathrm{Z}+2$ and $\mathrm{Z}-2$ alleles may be in linkage with a mutation in or around this regulatory element. The induction of ALR2 
transcription and the accumulation of sorbitol are probably part of the normal physiological osmoregulatory mechanism, whereby renal tubular cells adjust to the intraluminal hyperosmolality during urinary concentration. However, the osmotic stress in the nerve that occurs during hyperglycaemia may be directly related to the efficiency of the AR-ORES. An ORORE which is inefficient in driving ALR2 transcription is less likely to lead to an increased accumulation of sorbitol. By contrast, an overefficient AR-ORE will lead to an increased accumulation of sorbitol in the nerve and start the irreversible damage to the tissue.

\section{Conclusion}

In conclusion, our results show that the 5'ALR2 locus is associated with diabetic neuropathy. This suggests that the events leading up to tissue damage in the kidney and nerve may have a common pathway, by contrast with retinopathy which is only weakly associated with this marker. This may be a reflection of the sensitivity of the different tissues to the diabetic milieu. Identification of genetic markers that may predict susceptibility to diabetic neuropathy may have an important role in imposing the diagnosis and treatment of this debilitating condition.

This work was funded by grants from the Diabetes Foundation, Northcott Devon Medical Foundation, and a charitable donation from Zeneca Pharmaceuticals.

1 Tesfaye S, Stevens LK, Stephenson JM, et al, and the EURODIAB IDDM Study Group. Prevalence of diabetic peripheral neuropathy and its relation to glycaemic control and potential risk factors: the EURODIAB IDDM complications study Diabetologia 1996;39:1377-84.

2 Greene DA, Sima AAF, Pfeifer MA, et al. Diabetic neuropathy. Ann Rev Med 1990;41:303-17.

3 The DCCT Research Group. The effect of intensive The DCCT Research Group. The effect of intensive treatment of diabetes on the development and progression of long-term complications in insulin-depen
mellitus. N Engl f Med 1993;329:977-86.

4 Greene DA, Lattimer SA, Sima AAF. Sorbitol, phosphoinositides and sodium-potassium-ATPase in the pathogeninositides and sodium-potassium-ATPase in the pathogenesis of

5 Dvornik D. Hyperglycaemia in the pathogenesis of diabetic complications In: Porte D, ed. Aldose reductase inhibition: an approach to the prevention of diabetic complications. New York McGraw-Hill, 1987:7-151.

6 Cameron NE, Cotter MA, Low PA. Nerve blood flow in early experimental diabetes in rats: relation to conduction deficits. Am f Physiol 1991;261:E1-8.

7 Dyck PJ. Hypoxic neuropathy: does hypoxia play a role in diabetic neuropathy? Neurology $1989 \cdot \mathbf{3 9} \cdot 111-8$

8 Nishimura C, Lou MF, Kinoshita JH. Depletion of myo-inositol and amino acids in galactosemic neuropathy. f Neurochem 1987;49:290-5.

9 Boel E, Selmer J, Flodgaard HJ, et al. Diabetic late complications: will aldose reductase inhibitors or inhibitors of advanced glycosylation endproduct formation hold promise? ₹ Diabetes Complications 1995;9:104-29.

10 van-Gerven JM, Tion-A-Tsien AM. The efficacy of aldose reductase inhibitors in the management of diabetic complications. Comparison with intensive insulin treatment and pancreatic transplantation. Drugs Ageing 1995;6:9-28.

11 Baynes JW. Role of oxidative stress in the development of complications of diabetes. Diabetes 1991;40:405-12.

12 Corbett JA, Tilton RG, Change K, et al. Aminoguanidine, a novel inhibitor of nitric oxide formation, prevents diabetic vascular dysfunction. Diabetes 1992;41:552-6.

13 Williamson JR, Chang K, Frangos M, et al. Hyperglycaemic pseudohypoxia and diabetic complications. Diabetes 1993; 42:801-13

14 Cameron NE, Cotter MA. The relationship of vascular changes to metabolic factors in diabetes mellitus and their role in the development of peripheral nerve complications. Diabetes Metab Rev 1994;10:189-224.

15 Yagihashi S, Yamagishi S-I, Wada R, et al. Galactosemic neuropathy in transgenic mice for human aldose reductase. Diabetologia 1996;45:56-9.
16 Bohren KM, Bullock B, Wermuth B, et al. The aldo-keto reductase superfamily. The cDNAs and deduced amino acid sequences of human aldehyde and aldose reductases. $\mathcal{F}$ Biol Chem 1989;264:9547-51.

17 Chung S, LaMendola J. Cloning and sequence determination of human placental aldose reductase gene. $\mathcal{F}$ Biol Chem 1989;264:14775-7.

18 Nishimura C, Matsuura Y, Kokai Y, et al. Cloning and expression of human aldose reductase. $7 \mathrm{Biol}$ Chem 1990;265:9788-92.

19 Graham A, Brown L, Hedge PJ, et al. Structure of the human aldose reductase gene. f Biol Chem 1991;266:6872-

20 Graham A, Heath P, Morten JEN, et al. The human aldose reductase gene maps to chromosome $7 \mathrm{q} 35$. Hum Genet 1991;86:509-14.

21 Bateman JB, Kojis T, Heinzmann C, et al. Mapping of ldose reductase gene sequences to human chromosomes $1,3,7,9,11$, and 13. Genomics 1993;17:560-5.

22 Hibberd ML, Millward BA, Wong FS, et al. T-cell receptor constant $\beta$-chain polymorphisms and susceptibility to type I diabetes. Diabet Med 1992;9:929-33.

23 Patel A, Ratanachaiyavong S, Millward BA, et al. Polymorphisms of the aldose reductase locus (ALR2) and susceptibility to diabetic microvascular complications. Adv Exp Med Biol 1993;328:325-32.

24 Patel A, Hibberd ML, Millward BA, et al. Chromosome $7 \mathrm{q} 35$ and susceptibility to diabetic microvascular complications. F Diabet Complications 1996;10:62-7.

25 Heesom AE, Hibberd ML, Millward BA, et al. A polymorphism in the 5 'end of the aldose reductase gene is strongly associated with the development of diabetic nephstrongly associated with the development of diabetic
ropathy in type I diabetes. Diabetes 1997;46:287-91.

26 Ko BC-B, Lam KS-L, Wat NM-S, Chung SS-M. An (A-C)n dinucleotide repeat polymorphic marker at the 5 'end of the aldose reductase gene is associated with earlyonset diabetic retinopathy in NIDDM patients. Diabetes 1995;44:727-32.

27 National Diabetes Data Group. Classification and diagnosis of diabetes mellitus and other categories of glucose intolerance. Diabetes 1979;28:1039-44.

28 Tiwari JL, Terasaki PI. The data and statistical analysis. In: Tiwari JL, Terasaki PI, eds. HLA and disease associations. New York: Springer Verlag, 1985:18-27.

29 Greene DA, Winegrad AI. Effects of acute experimental diabetes on composite energy metabolism in peripheral nerve axons and Schwann cells. Diabetes 1981;30:967-74.

30 Greene DA. Metabolic abnormalities in diabetic peripheral nerve: relation to impaired function. Metabolism 1983;32: nerve: re.

31 Greene DA, Lattimer SA. Impaired energy utilisation and Na-K-ATPase in diabetic peripheral nerve. Am $\mathcal{F}$ Physiol 984;246:E311-8

32 Tomlinson DR, Sidenius P, Larsen JR. Slow component-a of axonal transport, nerve myo-inositol and aldose reductase inhibition in streptozotocin-diabetic rats. Diabetes 1986;34: 398-402.

33 Finegold D, Lattimer S, Nolle S, Bernstein M, Greene DA. Polyol pathway activity and myo-inositol metabolism. Diabetes 1983;32:988-92.

34 Greene DA, Lattimer SA. Action of sorbitol in diabetic peripheral nerve. Relationship of polyol (sorbitol) pathway inhibition to a myo-inositol-mediated defect in sodiumpotassium ATPase activity. Diabetes 1984;33:712-6.

35 Chakrabarti S, Sima AAF, Nakajima T, et al. Aldose reductase in the BB rat; isolation, immunological identification ase in the BB rat; isolation, immunological identification logia $1987 ; 30: 244-51$.

36 Sima AAF, Bril V, Nathanial V, et al. Regenration and repair of myelinated fibers in sural nerve biopsies from patients with diabetic neuropathy treated with an ARI. $N$ Engl $\mathcal{F}$ Med 1988;319:548-55.

37 Nicolucci A, Hohman TC, Carinci F, et al. The efficacy of Tolrestsat in the treatment of diabetic peripheral neuropathy. Diabetes Care 1996;19:1091-6.

38 Dyck PJ, Zimmerman BR, Vilen TH, et al. Nerve glucose, fructose, sorbitol myo-inositol and fiber degenration and regeneration in diabetic neuropathy. $N$ Engl $f$ Med 1988;319:542-8.

39 Burg MB, Kador PF. Sorbitol, osmoregulation, and the complications of diabetes. 7 Clin Invest 1988;81:635-40.

40 Moriyama T, Garcia-Perez A, Burg MB. Osmotic regulation of aldose reductase protein synthesis in renal medullary cells. F Biol Chem 1989;264:16810-4.

41 Moo Kwon H, Yamauchi A, Uchida S, et al. Renal Na-myoinositol cotransporter mRNA expression in Xenopus oocytes: regulation by hypertonicity. Am f Physiol 1991; 260:F258-63.

42 Hamada Y, Kitoh R, Raskin P. Crucial role of aldose reductase activity and plasma glucose level in sorbitol accumulation in erythrocytes from diabetic patients. Diabetes 1991;40:1233-40.

43 Hamada Y, Kitoh R, Raskin P. Association of erythrocyte aldose reductase activity with diabetic complications in type 1 diabetes mellitus.Diabet Med 1993;10:33-8.

44 Ko BC-B, Reupp B, Bohren KM, et al. Identification and characterisation of mulitiple osmotic response sequences in the human aldose reductase gene. F Biol Chem 1997;272. 16431-7. 